\title{
A NOVEL SLITTED TOOTH CORE DESIGN TO IMPROVE THE TORQUE-SPEED CHARACTERISTIC OF SQUIRREL CAGE INDUCTION MOTOR
}

\author{
Asim Gokhan Yetgin ${ }^{1}$, Mustafa Turan ${ }^{2}$ \\ ${ }^{I}$ Dumlupinar University, Department of Electrical and Electronics Engineering, Kutahya, TURKEY \\ ${ }^{2}$ Sakarya University, Department of Electrical and Electronics Engineering, Sakarya, TURKEY
}

gokhan.yetgin@dpu.edu.tr (Asim Gokhan YETGIN)

\begin{abstract}
In this study, a new design was suggested in order to improve the performance of induction motors. In these new designs, slits were applied in the middle of stator and rotor tooth parts. In these slitted models, the depth and width of slits were optimized by Finite Element Method Magnetics (FEMM) by using Finite Elements Method (FEM). Starting torque, pull-out torque, rated torque and torque-speed characteristics of the new motor model formed with the proposed slitted construction and reference motor model are given in comparison. The motor model is made with 56 slits which have different depth and width to see the effects of slits in the stator and rotor. In modeling, $3 \mathrm{~kW}$ squirrel-cage induction motor was used. As a result of modeling, increase in the coupling flux provided $2.085 \%$ and $4 \%$ increase especially in pull-out and rated torque values respectively.
\end{abstract}

Keywords: Finite Element Method, Induction Motor, Slitted Tooth Core Design, Torque-Speed Characteristic.

\section{INTRODUCTION}

Due to its robustness, the simplicity of its structure, its low cost and which does not need a regular maintenance, the induction motors are commonly used in many industrial applications in a wide range. The improvement of the power electronics and the advance of technologies of numerical controls improve its performance related torque and its controllability [1]. Today several approaches have still been developed and various studies have been carried out in order to develop the performance (torque, efficiency etc.) of induction motors. Yetgin and Canakoglu analyzed the impacts of the steel sheet plates, which have two different characteristics and are used in the industry on engine performance. They proved that a $0.7 \%$ improvement in the efficiency value in the rated operation point of the motor was ensured with the sheet plate, whose lost power value and magnetization characteristics are more preferable [2]. Kim and friends optimized the stator slot geometry in order to reduce stator iron and copper losses, including harmonic losses. They proved that a $2.22 \%$ decrease is achieved in stator iron and stator winding losses, due to the optimized stator slot geometry [3]. Sundaram and Navaneethan analyzed the motor performance using new slot geometry in an underwater induction motor. They stated that the magnetization current can decrease, and the efficiency value can increase by $5 \%$ with the new stator geometry they suggested [4]. Boglietti and friends outlined how the electromagnetic design of a three-phase induction motor is effectuated [5]. Benallal et al. [6] analyzed the impact of the air gap induction and the relative stator bore diameter values of the induction motor on motor performance. They analyzed the impacts of air gap length on the main inductance, stator and rotor inductance, current, moment, output power and efficiency of the induction motor [7]. Aho and friends proved that a $1.5 \%$ increase can be achieved in the efficiency value by changing the solid rotor end iron length value of the solid rotor induction motor [8]. They analyzed the impact of stator winding and stator bore diameter values of the induction motor on motor performance [9]. Marcic et al. analyzed the impact of different stator and rotor slot geometry combinations of the induction motor on motor performance [10]. Yamazaki was reported how the motor losses change in slot and slotless structures of solid rotor induction motor, and skewed and non-skewed structure of the induction motor with squirrelcage [11]. They implemented a new design using a genetic algorithm in their studies and optimized the losses, power factor and efficiency of the induction motor [12]. In his $\mathrm{Ph}$. D. study, He analyzed how a motor performance change by opening slits in the stator and rotor tooth of the induction motor. He also illustrated that the efficiency of the slitted motor increased by $1.89 \%$ in comparison to the reference motor [13]. They analyzed the impact of harmonics in the induction motor on motor performance and stated that motor temperature increases in direct proportion to the harmonic level, shortening motor life [14]. They analyzed the impact of space harmonics on transient electromagnetic moment [15]. In his post graduate study, He analyzed how to design the induction motor step-by-step, how design parameters affect motor performance, and analyzed the designs using the finite element method [16]. He analyzed changes in the stator current for different values of saturation coefficients [17]. Sarbu and friends analyzed the impact of windings (equal lapped coils, concentric coils), which were obtained by connecting the bobbins in different structures, on the 
motor performance [18]. Parasiliti et al. analyzed the change in the induction motor performance surfaced when different steel (standard-premium) and cage (aluminum-copper) are used [19]. They studied the effect of different skew angles on the induction motor performance. They analyzed the axially non-uniform fundamental and harmonic field distribution characteristics at typical locations in the core parts by using time stepping finite element method [20]. In their studies, they analyzed the impact of different rotor designs on induction motor rotor slot harmonics and compared these impacts with the values they obtained through experimental methods [21]. Huang et al. used the induction motor mathematical method in their study and optimized (identification) the equivalent circuit parameter with genetic algorithm [22]. They solved 2-D heat flow in the stator part of induction motor by using finite element analysis [23]. Han and friends present to reduce the material cost of the induction motor by using multi objective genetic algorithm and equivalent circuit method. Efficiency and power factor are achieved to the aim and the material cost is reduced about 5\% compared with the initial model [24]. They investigate the application of genetic algorithm for the estimation of steady-state models of induction motor [25]. Recently, to improve induction motor performance through alternative core design some other approaches have been used such as magnetic barriers, cut-outs and slits. Those designs have been applied especially on solid rotor induction motor [26], switched reluctance motor [27], and hybrid excitation synchronous motors [28]. In the literature, until, there is no usage of slitted design for laminated core squirrel cage induction motors except for author's papers. A few studies using slitted design are examined below for different motors.

In their study, by opening slit in the stator and rotor tooth of the induction motor and reduced the zigzag fluxes, which arise in the air gap of the motor, by $6.123 \%$, ensuring a $2.041 \%$ improvement in the coupling flux. With the point measurements in terms of their flux densities, it was illustrated that less strain is present compared to the reference motor [29]. In their study, the motor models reformed with the proposed shape design were analyzed with FEMM software programme that uses finite elements method. It was found at the end of the analyses that when the optimum slit width value was $0.10 \mathrm{~mm}$, motor efficiency gave better results compared with other slit width values. The increase in slit width caused saturations in motor teeth and thus caused to worsen the motor efficiency. It was decided at the end of different modeling that the depth of the slits used in the proposed slitted motor models should be almost the same height as stator and rotor height. Optimum slit value was determined as $15.00 \mathrm{~mm}$. At the end of the modeling, $1.869 \%$ improvement was obtained in the motor models that had $15.00 \mathrm{~mm}$ slit depth and $0.10 \mathrm{~mm}$ slit width compared with the efficiency values of reference model at rated operation point [30]. Aho and friends examined the electromagnetic torque change by adding slits to solid rotor induction motor rotor structure in their study. They have shown that electromagnetic torque could be improved by $6 \%$ and power factor could slightly be increased when the number of rotor slits increased from 28 to 36 . Furthermore, they argued that saturation occurs between slits when more rotor slit number is available and it worsens the electromagnetic performance [31]. In his study, Zaim evaluated the performance of solid rotor induction motor that has various power, slit number, depth and width by using FEM. He showed that while the increase in slit width increased the torque of motor in the models that have low number of slit, it decreased the torque of motor in the models that have high number of slit. He also stated that when the slit depth was increased, the torque first increased and then it decreased [32]. In their study, Chan and Hamid examined the current, torque and magnetic flux density changes by slitting in various numbers in the rotor structure of switched reluctance motor by using FEM. In the study, they stated that a flat topped wave form was obtained in both flux and torque graphics for five slitted models and the output power increased by $16 \%$ (without increase in top value of current). Moreover, they stated that the saturation in rotor could be controlled by changing the slit number [27]. They suggested slitted structure model in order to prevent the armature reaction in hybrid excitation synchronous machine. They stated that the effect of armature reaction could be reduced by making flux line longer with slitted structure [28].

The most important performance criterion of induction motor is the torque values. There are many parameters affecting starting, pull-out and rated torque. Frequency $f_{1}$, number of poles $\mathrm{p}$, applied voltage $\mathrm{V}_{1}$, stator and rotor resistances $R_{1}, R_{2}$ and leakage reactances $X_{1}, X_{2}$, slip $s$ are the parameters affecting torque changes. The general torque $\mathrm{T}$ formula was given in Equation 1. In the statement, $\mathrm{n}_{\mathrm{s}}$ and $\mathrm{s}$ represent shaft speed and slip respectively.

$$
T=\frac{3 p}{2 \pi f_{1}} \frac{1}{s} R_{2} \frac{V_{1}^{2}}{\left(R_{1}+\frac{R_{2}}{s}\right)^{2}+\left(X_{1}+X_{2}\right)^{2}}
$$

Especially leakage reactances greatly affect the torque produced by motor. So, in design process, leakage reactances should be kept to a minimum. Magnetization reactance $X_{m}$ should be as high as possible and $X_{1}$ and $X_{2}$ values should be as low as possible in order to get maximum motor performance. Since short circuit reactance $X_{k}$ is the criterion for the maximum torque of the machine, the designers determine the machine sizes and windings in such a way that $X_{1}+X_{2}$ reactances can have a certain value and they try to make $X_{m}$ reactance as big as possible. Moreover, the growth of $X_{2}$ reduces the maximum torque and so the performance of the machine is negatively affected. When $X_{1}$ increases, flux linkage which is the multiplier of torque is reduced [33].

In this study, a new core design is developed in order to improve the torque-speed characteristic of induction motor. In the core design, stator and rotor slot shapes, air-gap length, stator outside diameter and shaft diameter etc. values are not changed. Starting, pull-out and rated torque values 
gained from reference motor model and proposed slitted motor models and the change of torque-speed characteristics are given in comparison. Induction motor design is getting improved toward to excellence during the century. Proposed slitted tooth core design in the paper, not only improves the torque-slip characteristics of the induction motor, but also improves some other performance parameters which are discussed in the paper. Energy efficiency and quality matters are important issues in the millennium. The proposed design will be applicable since it offers a few points of improvements in the journey of excellency for the high induction motors.

\section{FEM AND TORQUE CALCULATION}

The FEM is one of the most popular methods for computer simulation. This method is suitable for solving the problem involving electric and magnetic field. Finite Element Analysis (FEA) provides a certain numerical technique for engineering design [34]. There are many studies in the literature using FEMM program [35-39] and the results obtained from comparing the experimental and simulations are supported by each other. When FEMM simulation and experimental study were compared by [38], error rate was found as $0.065 \%$.

\subsection{FEMM Process}

Motor models are described with length, problem type, frequency and angle. After definition of the problem, materials properties, B-H curve, values of the conductivity are assigned and then circuit, number of turns in the stator windings must also be defined at this stage. After that FEMM has an automatic mesh generator, which generates a uniform mesh for the whole geometry. The boundary condition is set, which minimizes the model size as shown in Figure 1 [34]. In Figure 1, W, Al, Air and Iron are present windings, aluminum, air and iron core respectively.

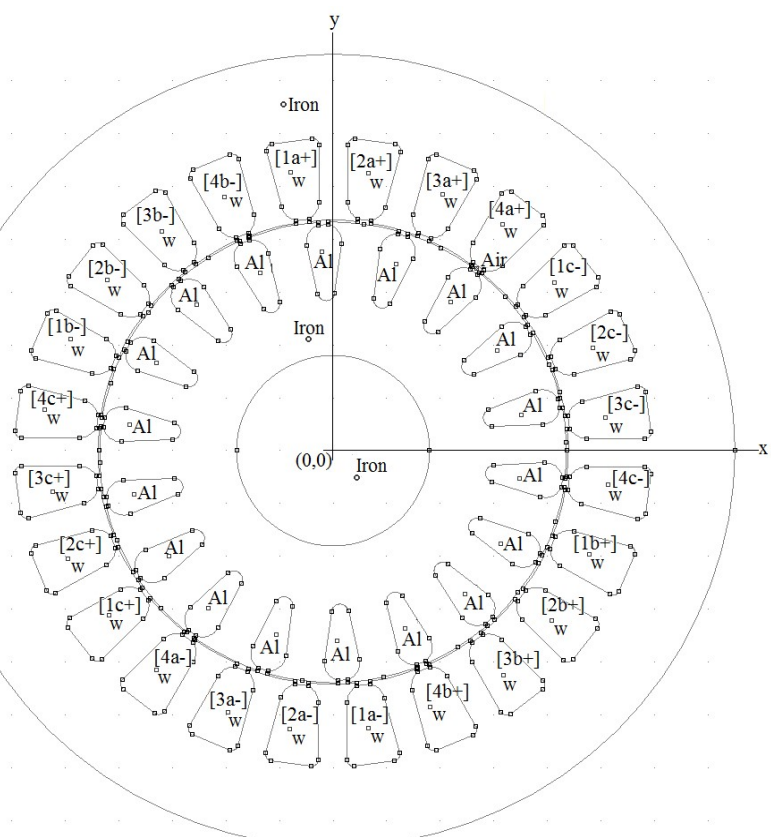

In solving stage, the FEMM program starts to solve the formulated field equations [34]. The mesh distribution is given in Figure 2 for the reference motor.

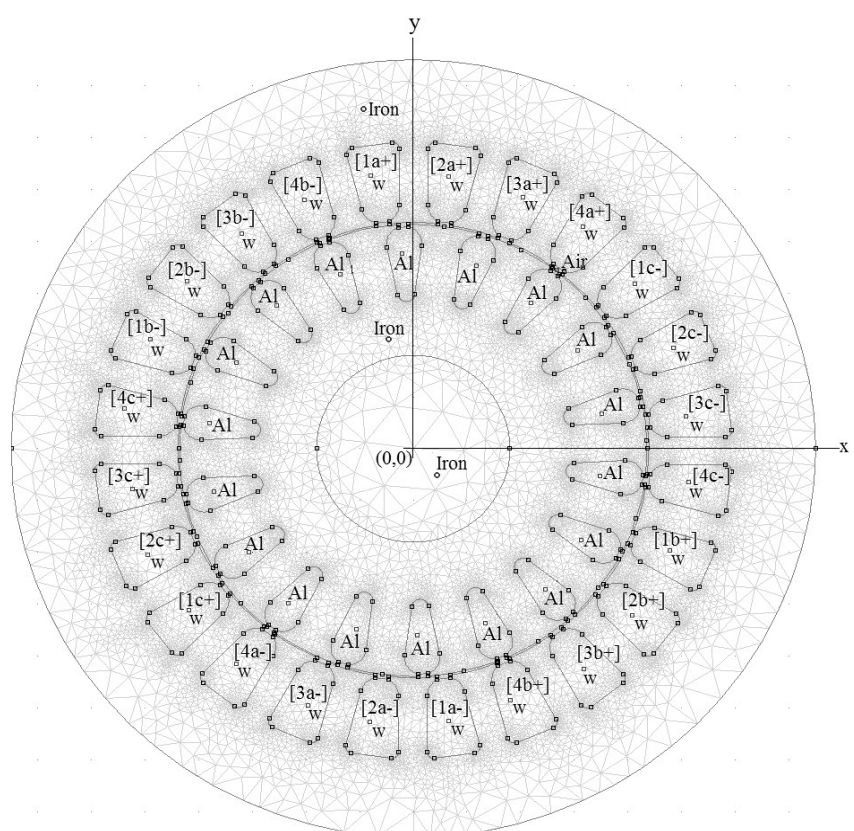

Fig -2: Finite element mesh distribution for the reference motor

The measurement and required parameters are calculated by using solver process in the last stage [34]. In this study, for mesh distribution, 80422 nodes, 160318 elements are created for the reference motor and 137260 nodes, 274008 elements are created for the slitted motor, the solver precision is chosen $1 \mathrm{e}^{-008}$ and the minimum angle for triangles are chosen $30^{\circ}$.

\subsection{Torque Calculation}

Electromagnetic torque in an electrical machine can be acquired with the evaluation of Maxwell Stress Tensor along with a contour. In this method, torque is directly calculated with the distribution of magnetic field. Torque is evaluated with integration of the force density on the surface surrounding the related part (for three dimensional models) or on a contour (two dimensional problems) [40].

$$
F=\mathbb{T}_{C}\left[\frac{1}{\mu_{0}} B(B . n)-\frac{1}{2 \mu_{0}} B^{2} . n\right] d C
$$

When the integrand of Equation 2 is taken, normal and tangent force intensity are decomposed and it plays an important role in the analytical and mathematical calculations of the force and the torque. These components of force density are generally known as Maxwell Stresses and they are shown as follows [41].

$$
f_{n}=\frac{1}{2 \mu_{0}}\left(B_{n}^{2}-B_{t}^{2}\right)
$$

Fig -1: Problem parameters for motors 


$$
f_{t}=\frac{1}{\mu_{0}} B_{n} B_{t}
$$

Torque is acquired with the multiplication of tangential force by the radius of contour in Equation 5 [42]. In the statements, $\mathrm{B}_{\mathrm{n}}$ and $\mathrm{B}_{\mathrm{t}}, \mu_{0}, \mathrm{C}, \mathrm{n}$ and $\mathrm{L}$ represent normal and tangential components of magnetic flux density, magnetic conductivity of space, integration contour, unit vector and stack length respectively.

$$
T=\left[\frac{r}{\mu_{0}} \int_{C} B_{n} B_{t} d_{C} n\right] L
$$

In this study, the torque values of reference and slitted motor models modeled with FEMM [43], software package were found by using Maxwell Stress Method. The obtained values are calculated at the nominal operating point.

\section{PROPOSED SLITTED CONSTRUCTION}

New tooth geometry is proposed in order to improve torquespeed characteristic which is the most important performance criterion in induction motor without using higher grade lamination sheets. By proposed slitted construction, it is aimed to overcome rotor reaction effects by decreasing quadrature axis flux such as leakage and zigzag flux in the air gap and, to increase d axis coupling flux which is the major parameter of induced torque. Thus, induction motor performance will be improved by using slitted core design. To model slitted core design, a $3 \mathrm{~kW}$ squirrel cage induction motor was used and the motor parameters were given in Table 1 .
Table -1: Parameters of the Induction Motor

\begin{tabular}{|l|l|l|}
\hline Motor parameters & Symbol & Value \\
\hline Voltage (V) & $\mathrm{V}_{1}$ & 380 \\
\hline Current (A) & $\mathrm{I}_{1}$ & 6.6 \\
\hline Power factor & Cos $\theta$ & 0.88 \\
\hline Frequency (Hz) & $\mathrm{f}_{1}$ & 50 \\
\hline Speed (rpm) & $\mathrm{n}_{\mathrm{r}}$ & 2844 \\
\hline Number of poles & $2 \mathrm{p}$ & 2 \\
\hline Winding connection & & Star \\
\hline Stator slot shape & & Trapezoidal \\
\hline Rotor slot shape & & Round \\
\hline Number of stator slot & $\mathrm{N}_{\mathrm{s}}$ & 24 \\
\hline Number of rotor slot & $\mathrm{N}_{\mathrm{r}}$ & 18 \\
\hline
\end{tabular}

Slits were applied in the middle of both stator and rotor teeth of rotor squirrel-cage induction motor. In the models, slit depth were determined from $6.25 \mathrm{~mm}$ to $23.00 \mathrm{~mm}$. The slit widths were the models changing from $0.09 \mathrm{~mm}$ to 2.50 $\mathrm{mm}$. For each slit depth models having slit width were created. The aim is to determine which slit depth and width provides the most efficient motor torque-speed. In this respect, an optimization work carried out on 56 different designs was presented in Table 2. Motor models having different slit depth and width were shown as "o". Slit depth and width values are chosen to be made by laser cutting.

\begin{tabular}{|c|c|c|c|c|c|c|c|c|c|c|}
\hline \multirow{2}{*}{$\begin{array}{l}\text { Width of } \\
\text { slit }(\mathrm{mm})\end{array}$} & \multicolumn{10}{|c|}{ Depth of slit (mm) } \\
\hline & 6.25 & 7.50 & 11.25 & 13.12 & 15.00 & 16.87 & 18.75 & 19.60 & 21.00 & 23.00 \\
\hline 0.09 & & o & 0 & o & o & o & o & & & \\
\hline 0.10 & o & o & 0 & o & o & o & o & o & o & o \\
\hline 0.15 & $\mathrm{o}$ & o & $\mathrm{o}$ & o & o & $\mathrm{o}$ & o & $\mathrm{o}$ & 0 & $\mathrm{o}$ \\
\hline 0.25 & & 0 & $\mathrm{o}$ & 0 & 0 & 0 & 0 & & & \\
\hline 0.50 & & 0 & 0 & 0 & 0 & 0 & 0 & & & \\
\hline 1.00 & & $\mathrm{o}$ & 0 & $\mathrm{o}$ & $\mathrm{o}$ & o & o & & & \\
\hline 1.50 & & o & 0 & o & 0 & o & o & & & \\
\hline 2.50 & & o & o & 0 & o & 0 & o & & & \\
\hline
\end{tabular}

Table -2: Motor Models Having Different Slit Depth and Width

As a result of various modeling for slit depth of stator and rotor, it is concluded that slit depths should be about the same with slots $(15.00 \mathrm{~mm})$. Modeled samples show that the best slit width is $0.10 \mathrm{~mm}$ preventing saturation. It is seen that flux lines complete the circuits around slits at the models which slit depth is selected smaller than slot height values. At the models which slit depth is high since slit twisted inward of stator and rotor back iron yoke parts, it has been caused saturation at these parts. With increasing slit width, saturation occurred in the stator and the rotor teeth. As a consequence, it is seen that obtained motor performance values is worsening [13]. Reference motor model whose analysis were carried out with FEMM software package is shown in Figure 3 and the motor model on which the proposed slitted structure was applied is shown in Figure 4. The analyses are carried out with the same

values without changing the parameters such as stator and rotor slot shapes, internal-external diameter, number of turns etc. Detail of stator and rotor slits are given in Figure 5. 


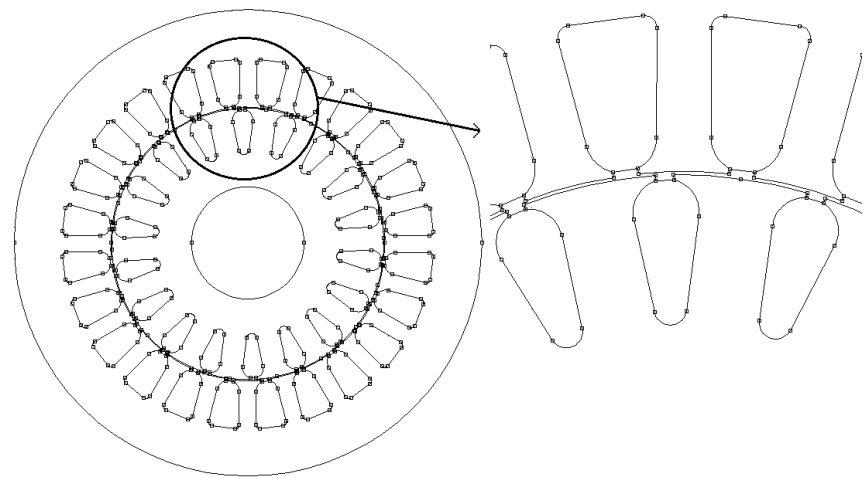

Fig -3: The reference motor (R.M.) model

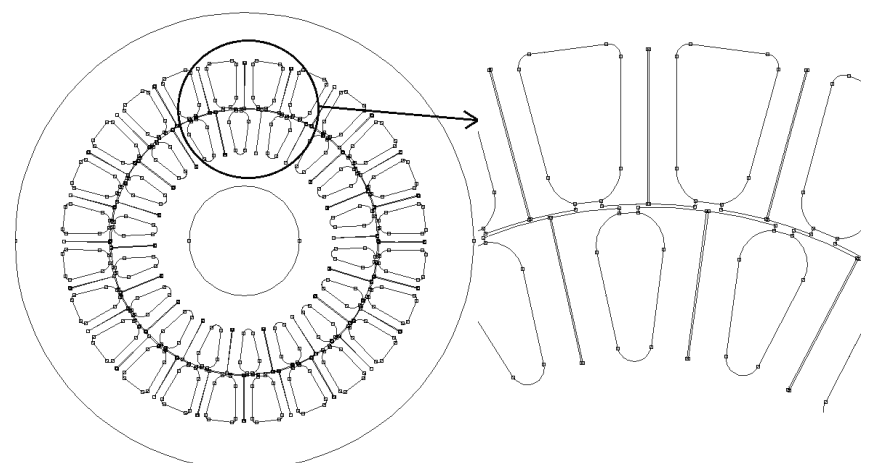

Fig -4: Proposed slitted motor (S.M.) model (15.00 mm slit depth, $0.1 \mathrm{~mm}$ slit width)

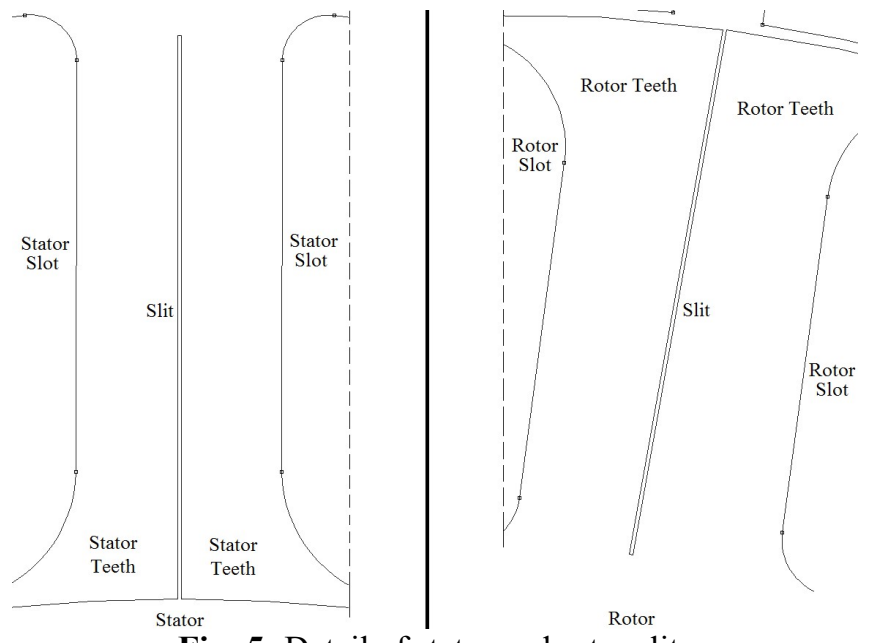

Fig -5: Detail of stator and rotor slits

\subsection{The Advantage of Proposed Slitted}

\section{Construction [13]}

- The more effective using of the magnetic flux in core: reduction of saturation, better flux distribution at the teeth, reduction of rotor reaction.

- Increased zigzag path reluctance. That results in low additional losses.

- Decreased saturation. That results in reduced core loss.

- Smaller slip. That causes less rotor copper loss.

- Lowered total losses. That results in better efficiency.

- Improved overall performance on the rated operating point.
- Smaller leakage reactance. That results in a better speedtorque characteristic.

- Increased power factor via increase output power. That causes improvement in reactive power consumption.

\subsection{The Disadvantage of the Proposed Slitted}

\section{Construction [13]}

- For small power motors, the initial construction cost is slightly high owing to cut off the core with laser. However, the cost will be reduced in case of mass production.

- The analytical solution is difficult.

\subsection{Cut Out of Slits}

In proposed design, slits on the teeth of rotor and stator can be machined by laser cutting, wire cut EDM or water jet cutting machines. Sheets for small horsepower motors can be cut one by one or multiple at once up to $20 \mathrm{~mm}$ thicknesses. In application of proposed slitted design to high power motors, it is more convenient to use die cutting technics. Since stamping die mold is manufactured once, there will be no additional costs for high power motors in mass production.

\section{RESULTS and DISCUSSION}

Figure 6 and 7 illustrate the magnetic flux density distribution of the reference and the slitted motor models.

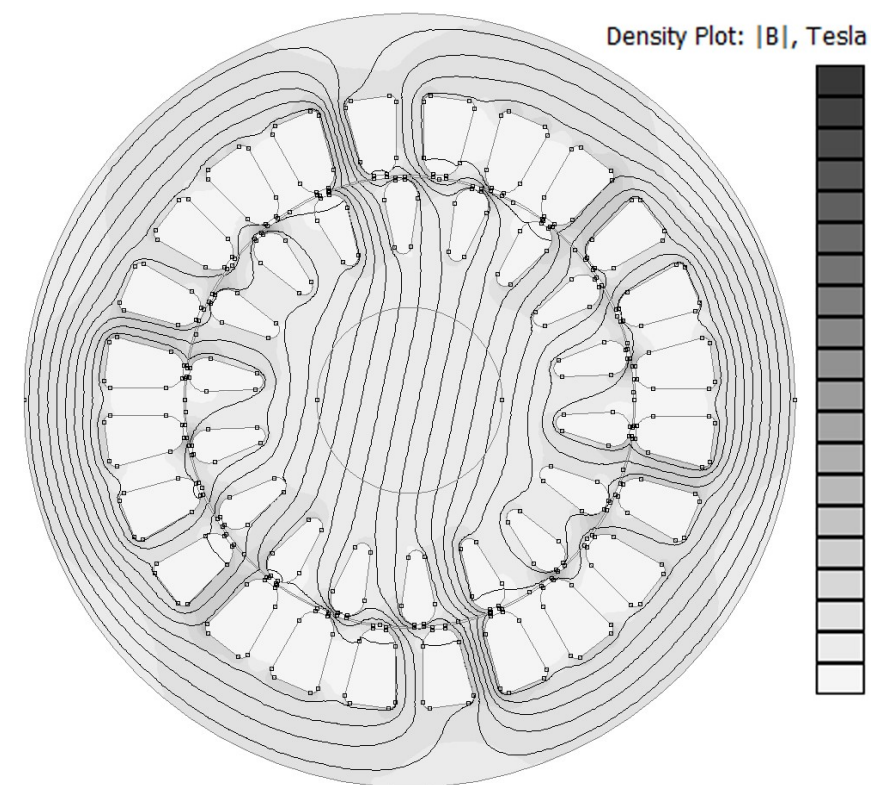

Fig -6: Magnetic flux density distribution of the reference motor model 


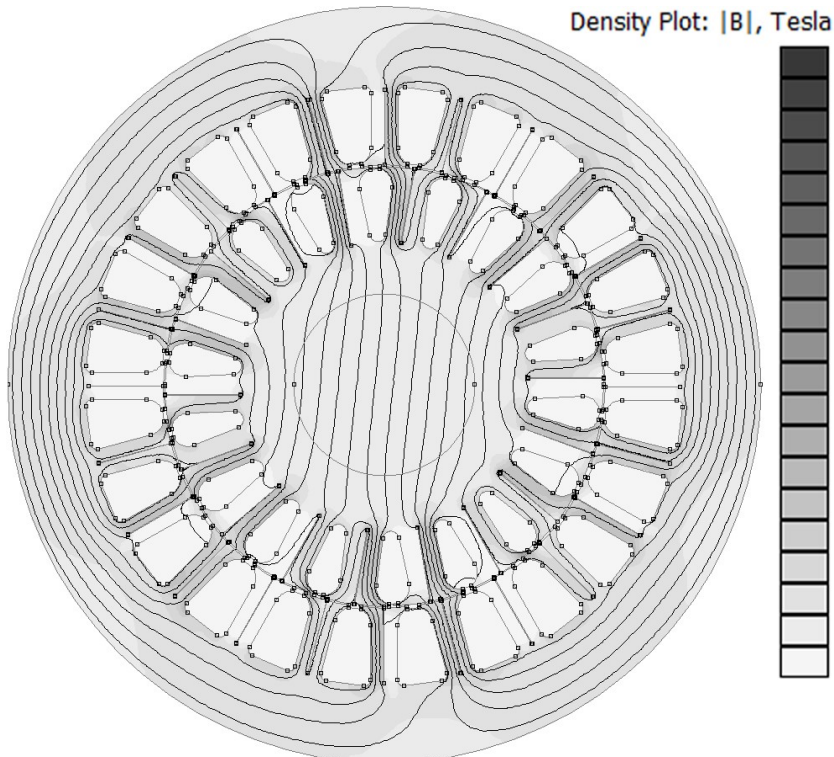

Fig -7: Magnetic flux density distribution of the slitted motor model which has $15.00 \mathrm{~mm}$ slit depth and $0.1 \mathrm{~mm}$ slit width

It can be easily seen from the figures that, magnetic field distribution in slitted motor model is more conditioned. Magnetic flux density in teeth and yoke parts of stator and rotor is lower than the reference motor's. However, magnetic flux density near the teeth tips in slitted model is higher than the reference motor's. This can be corrected by rounding slit tips. The stator and rotor reactances and relative difference values obtained using FEMM are given in Table 3. It is seen that the stator and rotor reactances value decreased by $2.460 \%$ with proposed slitted motor.

Table -3: Stator and Rotor Reactances

\begin{tabular}{|l|l|l|l|}
\hline $\begin{array}{l}\text { Motor } \\
\text { parameters }\end{array}$ & $\begin{array}{l}\text { Reference } \\
\text { motor }(\mathbf{o h m})\end{array}$ & $\begin{array}{l}\text { Slitted } \\
\text { motor }(\mathbf{o h m})\end{array}$ & $\begin{array}{l}\text { Relative } \\
\text { difference } \\
\mathbf{( \% )}\end{array}$ \\
\hline $\begin{array}{l}\text { Stator and rotor } \\
\text { reactances } \\
\left(X_{I}+X_{2}\right)\end{array}$ & 0.319 & 0.311 & -2.460 \\
\hline
\end{tabular}

The coupling flux for different points are given in Table 4 both motors [13].

Table -4: The Coupling Flux for Different Points

\begin{tabular}{|c|c|c|c|c|}
\hline \multicolumn{2}{|c|}{ Coordinates (mm) } & \multicolumn{2}{|c|}{ Coupling flux (mWb) } & \multirow{2}{*}{$\begin{array}{l}\text { Relative } \\
\text { difference } \\
(\%)\end{array}$} \\
\hline $\mathrm{x}$ & $\mathrm{y}$ & $\begin{array}{l}\text { Reference } \\
\text { motor }\end{array}$ & $\begin{array}{l}\text { Slitted } \\
\text { motor }\end{array}$ & \\
\hline-4.2 & 22.1 & 0.934937 & 0.954496 & 2.092 \\
\hline-21.7 & 10.6 & 0.973707 & 0.976006 & 0.236 \\
\hline 32.9 & 12.3 & 1.229049 & 1.307770 & 6.405 \\
\hline-16.9 & 30.7 & 1.363618 & 1.392062 & 2.085 \\
\hline 4.28 & 43.28 & 1.275455 & 1.293198 & 1.391 \\
\hline-27.6 & 32.9 & 1.355180 & 1.369690 & 1.070 \\
\hline
\end{tabular}

According to coupling flux values taken from various coordinates, coupling flux values which are occurred in slitted motor model are increased by $2.041 \%$ when compared with reference motor model. With decreasing of zigzag flux in slitted motor model, flux lines which flow air gap to rotor part increase and that is concluded with an increase in coupling flux.

In Figure 8, torque-speed characteristic curve obtained from reference and slitted motor models are presented [13].

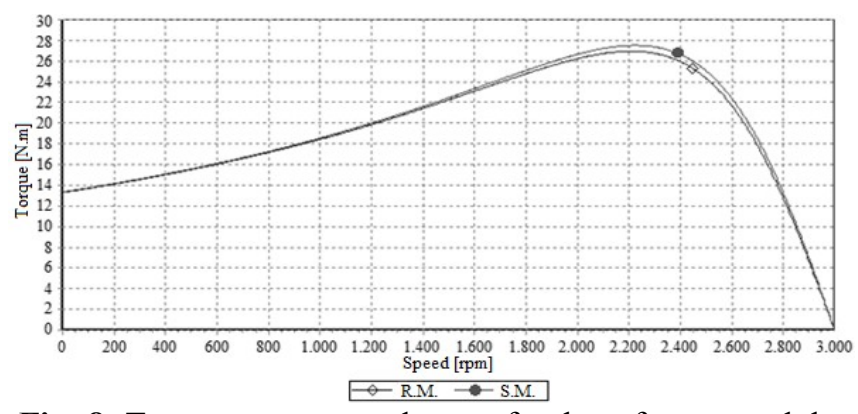

Fig -8: Torque versus speed curve for the reference and the slitted motor models

Starting, pull-out, rated torque values and their relative differences for reference motor model and proposed slitted motor models are shown in Chart 9 [13]

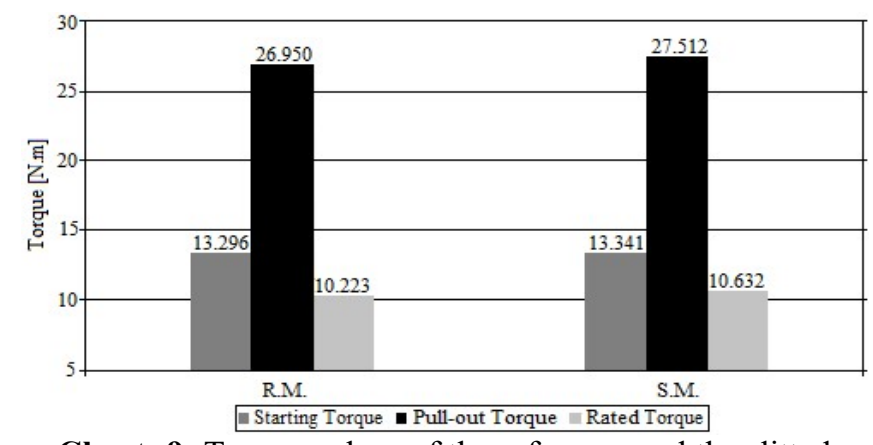

Chart -9: Torque values of the reference and the slitted motor models

\section{CONCLUSION}

In this study, a new teeth design is suggested so that the torque-speed characteristic which is one of the most important performance indicators of an induction motor could be improved. The re-engineered motor models with the suggested geometry are analyzed with FEMM software package and the following results were obtained.

The suggested slits constitute additional reluctance in zigzag flux paths and $6.123 \%$ decrease was seen in the zigzag permeance. Thus, it yields $2.460 \%$ reduction in the stator and rotor reactances values [29]. Some improvement is seen in the torque-speed characteristic of motor depending on the stator and rotor reactances reduction. As a result of the reduction of the zigzag flux in the air-gap, 2.041\% increase was obtained in the coupling flux with the realigning of the flux produced in the stator [13]. The increase in the coupling flux provided $2.085 \%$ and $4 \%$ increase especially in pull-out and rated torque values respectively. 


\section{REFERENCES}

[1]. Khedher, A., Mimouni, M. F. "Sensorless-adaptive DTC of double star induction motor". Energy Convers. Manage., vol. 51, pp. 2878-2892, 2010.

[2]. Yetgin, A. G., Canakoglu, A. I. "Steel sheets used in industrial applications effects on performance of induction motor and improvement of efficiency". 1th energy efficiency and quality symp., pp. 25-27, Kocaeli, Turkey, 2005.

[3]. Kim, J. W., Kim, B. T., Kwon, B. I. “Optimal stator slot design of inverter-fed induction motor in consideration of harmonic losses". IEEE Trans. Magn., vol. 41, no. 5, pp. 2012-2015, 2005.

[4]. Sundaram, M., Navaneethan, P. "On the influence of stator slot shape on the energy conservation associated with the submersible induction motors". Am. J. Appl. Sci., vol. 8, no. 4, pp. 393-399, 2011.

[5]. Boglietti, A., Cavagnino, A., Lazzari, M. "Geometrical approach to induction motor design". The 33rd annual conf. of the IEEE industrial electronics society, pp. 149-156, Taipe, Taiwan, 2007.

[6]. Benallal, M. N., Vaganov, M. A., Pantouhov, D. S., Ailam, E., Hamouda, K. "Optimal value of air gap induction in an induction motor". XIX int. conf. on electrical machines, pp. 1-4, Rome, Italy, 2010.

[7]. Pichler, P., Ebner, P., Weiss, H. "Comparison analytical and FEA calculation software as a tool for designing a high efficient induction machine". 44th int. conf. power electronics, intelligence motion, power quality, Nürnberg, Germany, 2001.

[8]. Aho, T., Nerg, J., Pyrhönen, J. "Optimizing the axial length of the slitted solid iron rotor". 2nd IEEE conf. on industrial electronics and applications, pp. 255-259, Harbin, China, 2007.

[9]. Muravleva, O., Muravlev, O. "Power effective induction motors for energy saving". 9th RussianKorean int. symp. on science and technology (KORUS 2005), pp. 358-362, Russia, 2005.

[10]. Marcic, T., Stumberger, B., Stumberger, G., Hadziselimovic, M., Zagradisnik, I. "The impact of different stator and rotor slot number combinations on iron losses of a three-phase induction motor at noload”. J. Magn. Magn. Mater., vol. 320, pp. 891-895, 2008.

[11]. Yamazaki, K. "Loss calculation of induction motors considering harmonic electromagnetic". Electr. Eng. Jpn., vol. 147, no 2, pp. 63-73, 2007.

[12]. Sivaraju, S. S., Devarajan, N. "Novel design of three phase induction motor enhancing efficiency, maximizing power factor and minimizing losses". Eur. J. Sci. Res., vol. 58, no. 3, pp. 423-432, 2011.

[13]. Yetgin, A. G. "Performance improvement of induction motor with slitted core design". Dissertation for the Doctoral Degree. Institute of Science, Sakarya, Turkey, 2010.

[14]. Mirzamani, H. O., Choobar, A. L. "Study of harmonics effects on performance of induction motors". 8th WSEAS int. conf. on circuits, Wisconsin, USA, 2004.

[15]. Villar, J. A. E., Roman, J. M., Iribarnegaray, L. S.
"Transient harmonic torques in induction machines: measurement and impact on motor performance". Electr. Eng., vol. 94, pp. 67-80, 2012.

[16]. Yetgin, A. G. "Design and finite element analysis of a three phase induction machine". MS Thesis, Institute of Science, Kütahya, Turkey, 2004.

[17]. Joksimovic, G. "Line current spectrum analysis in saturated three-phase cage induction machines". Electr. Eng., vol. 91, pp. 425-437, 2010.

[18]. Sarbu, M. A., Cistelecan, M. V., Wang, S., Demeter, E. "Part-winding starting of the three-phase squirrel cage induction motor: air gap magnetic field analysis". 11 th int. symp. on electromagnetic fields in electrical engineering, pp. 143-148, Maribor, Slovenia, 2003.

[19]. Parasiliti, F., Villani, M., Paris, C., Walti, O., Songini, G., Novello, A., Rossi, T. "Three-phase induction motor efficiency improvements with die-cast copper rotor cage and premium steel". Proc. of SPEEDAM'04 Symposium, pp. 338-343, Capri, Italy, 2004.

[20]. Zhao, H., Liu, X. F., Luo, Y., Chen, W. H., Baldassari, P. "Time-stepping finite element analysis on the influence of skewed rotors and different skew angles on the losses of squirrel cage asynchronous motors". Sci. Chin. Technol. Sci., vol. 54, no. 9, pp. 2511-2519, 2011.

[21]. Guldemir, H., Bradley, K. J. "The effect of rotor design on rotor slot harmonics in induction machines". Electr. Power Compon. Syst., vol. 29, pp. 771-788, 2001.

[22]. Huang, K. S., Kent, W., Wu, Q. H., Turner, D. R. "Parameter identification for FOC induction motors using genetic algorithms with improved mathematical model". Electr. Power Compon. Syst., vol. 29, pp. 247-258, 2001.

[23]. Sarkar, D., Bhattacharya, N. K. "Computation of thermal condition in an induction motor during stardelta starting". Electr. Power. Compon. Syst., vol. 35, pp. 1041-1060, 2007.

[24]. Han, P. W., Seo, U. J., Choi, J. H., Chun, Y. D., Koo, D. H., Lee, J. "Optimizing design variables for high efficiency induction motor considering cost effect by using genetic algorithm”. J. Electr. Eng. Technol., vol. 7, no. 6, pp. 948-953, 2012.

[25]. Jangjit, S., Laohachai, P. "Parameter estimation of three-phase induction motor by using genetic algorithm". J. Electr. Eng. Technol., vol. 4, no. 3, pp. 360-364, 2009.

[26]. Pyrhönen, J., Nerg, J., Mikkola, A., Sopanen, J., Aho, $\mathrm{T}$. "Electromagnetic and mechanical design aspects of a high-speed solid-rotor induction machine with no separate copper electric circuit in the megawatt range". Electr. Eng., vol. 91, pp. 35-49, 2009.

[27]. Chan, S., Hamid, M. N. "Finite element study on a two-phase switched reluctance motor with split rotor poles". Int. conf. on power electronics and drives systems, pp. 1156-1160. Malaysia, 2005.

[28]. Li, L., Foggia, A., Lebouc, A. K., Mipo, J. C., Kobylansky, L. "Some armature reaction compensation methods numerical design of experiments and optimization for a hybrid excitation 
machine". Int. electric machines and drives conf., pp. 832-838. Miami, United States, 2009.

[29]. Yetgin, A. G., Turan, M., Canakoglu, A. I. "A novel slitted tooth core design to decrease leakage flux in induction motor". J. Fac. Eng. Archit. Gazi Univ., vol. 27, no. 3, pp. 607-614, 2012.

[30]. Yetgin, A. G., Turan, M. "Efficiency optimization of slitted-core induction motor". J. Electr. Eng., vol. 65, no. 1, pp. 60-64, 2014.

[31]. Aho, T., Nerg, J., Pyrhonen, J. "The effect of the number of rotor slits on the performance characteristics of medium-speed solid rotor induction motor". 3rd IET int. conf on power electronics, machines and drives, pp. 515-519. Dublin, Ireland, 2006.

[32]. Zaim, M. E. "Non-linear models for the design of solid rotor induction machines". IEEE Trans. Magn., vol. 35, no. 3, pp. 1310-1313, 1999.

[33]. Turan, M. "The analysis of harmonic reactances and torques on the expanded equivalent circuit of the induction machine". MS Thesis, Institute of Science, Sakarya, Turkey, 1996.

[34]. Zakaria, Z., Mansor, M. S. B., Jahidin, A. H., Azlan, M. S. Z., Rahim, R. A. "Simulation of Magnetic Flux Leakage (MFL) analysis using femm software". IEEE symp. on industrial electronics and applications, pp. 481-486, Penang, Malaysia, 2010.

[35]. Singla, B. R., Marwaha, S., Marwah, A. "Design and transient analysis of cage induction motor using finite element methods". Int. conf. on power electronics, drives and energy systems, pp. 1-5, New Delphi, 2006.

[36]. Lubin, T., Berger, K., Rezzoug, A. "Inductance and force calculation for axisymmetric coil systems including an iron core of finite length". Prog. Electromagnet. Res. B, vol. 41, pp. 377-396, 2012.

[37]. Lee, H. I., Yoo, S. Y., Noh, M. D. "Toroidally-wound self-bearing BLDC motor with lorentz force". IEEE Trans. Magn., vol. 46, no. 6, pp. 2148-2151, 2010.

[38]. Saraiva, E., Chaves, M. L. R., Camacho, J. R. "Threephase transformer representation using femm, and a methodology for air gap calculation". Proc. of the int. conf. on electrical machines, pp. 1-6. Vilamoura, 2008.

[39]. Grilo, N., Sousa, D. M., Roque, A. "AC motors for application in a commercial electric vehicle: designing aspects". 16th IEEE Mediterranean electrotechnical conf., pp. 277-280, Yasmine, Hammamet, 2012.

[40]. Gurdal, O. "Design of electric machines", Atlas Press, 2001.

[41]. Fiser, R., Ferkolj, S. "Calculation of magnetic field asymmetry of induction motor with rotor faults". 9th Mediterranean electrotechnical conf., pp. 1175-1179. Tel-Aviv, 1998.

[42]. Dezhen, W., Pekarek, S. D., Fahimi, B. "A field reconstruction technique for efficient modeling of the fields and forces within induction machines". IEEE Trans. Energy Convers., vol. 24, no. 2, pp. 366-374, 2009.

[43]. Meeker, D. "Induction motor example", 2004.

\section{BIOGRAPHIES}

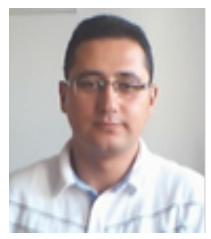

A. G. Yetgin was born in Kütahya, Turkey, in 1979. He received the B.Sc. and M.Sc. degrees in 2001 and 2004 from the Department of Electrical Electronics Engineering, Selcuk University, Konya, Turkey and Dumlupinar University, Kütahya, Turkey respectively. He received $\mathrm{Ph} . \mathrm{D}$. degree from Sakarya University. He is working as Assistant Professor in Department of Electrical Electronics Engineering, Dumlupınar University. His areas of research include optimization, design and modeling of electrical machines, finite element method and energy saving.

E-mail : gokhan.yetgin@dpu.edu.tr

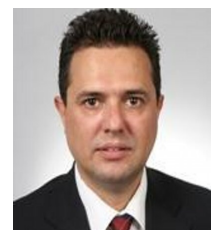

M. Turan was born in Babaeski, Turkey, in 1964. He has received B.S. degree from Istanbul Technical University, M.Sc. and Ph.D. degrees from Sakarya University, Turkey in the years 1987, 1994 and 2002 respectively, in Electrical Engineering. He is a faculty member of Electrical and Electronics Eng. Dept., Sakarya University, Turkey, since 2002, and currently serving as Assistant Professor. His research interests include design, performance analysis and optimization of electrical machines, power quality power system stability.

E-mail : turan@sakarya.edu.tr 